\title{
An NMR Method for the Quantitative Assessment of Intramolecular Hydrogen Bonding; Application to Physicochemical, Environmental, and Biochemical Properties
}

\author{
Michael H. Abraham, ${ }^{* \dagger}{ }^{\dagger}$ Raymond J. Abraham, ${ }^{\ddagger}$ William E. Acree, Jr., ${ }^{\S}$ Abil E. Aliev, ${ }^{\dagger}$ Al J. Leo," \\ and William L. Whaley ${ }^{\perp}$ \\ ${ }^{\dagger}$ Department of Chemistry, University College London, 20 Gordon Street, London WC1H OAJ, U.K. \\ ${ }^{\ddagger}$ Department of Chemistry, University of Liverpool, Crown Street, Liverpool L69 7ZT, U.K. \\ ${ }^{\S}$ Department of Chemistry, University of North Texas, 1155 Union Circle Drive \#305070, Denton, Texas 76203-5017, United States \\ "BioByte Corporation, 201 West Fourth Street \#204, Claremont, California 91711, United States \\ ${ }^{\perp}$ Department of Chemistry, Geosciences, and Physics, Tarleton State University, Box T-0540, Stephenville, Texas 76401, United \\ States
}

ABSTRACT: ${ }^{1} \mathrm{H}$ NMR chemical shifts have been obtained in the solvents deuterochloroform and dimethyl sulfoxide. The difference in the chemical shifts of an $\mathrm{OH}$ or $\mathrm{NH}$ group in these two solvents, $\Delta \delta=\delta(\mathrm{DMSO})-\delta\left(\mathrm{CDCl}_{3}\right)$, can be converted into the hydrogen bond acidity, $A$, of the group using the equation $A=$ $0.0065+0.133 \Delta \delta$. The NMR $A$ value, $A_{\mathrm{NMR}}$ can be used as a quantitative assessment of intramolecular hydrogen bonding. We list values of $\Delta \delta$ and $A_{\mathrm{NMR}}$ for 55 compounds containing an $\mathrm{OH}$ group and 60 compounds with an $\mathrm{NH}$ group. For the hydroxy compounds, if $A>0.5$ then the $\mathrm{OH}$ group is not part of an intramolecular hydrogen bond, but if $A<0.1$ then the $\mathrm{OH}$ group forms part of an intramolecular hydrogen bond. For $\mathrm{NH}$ compounds, if $A>0.16$ the $\mathrm{NH}$ group is not part of an intramolecular hydrogen bond, and if $A<0.05$ the $\mathrm{NH}$ group is part of an intramolecular hydrogen bond. No comparison compounds are needed, and the method is extremely simple. We further show how it is possible to relate intramolecular hydrogen bonding to the actual effect on values of a number of physicochemical, environmental, and biochemical properties.

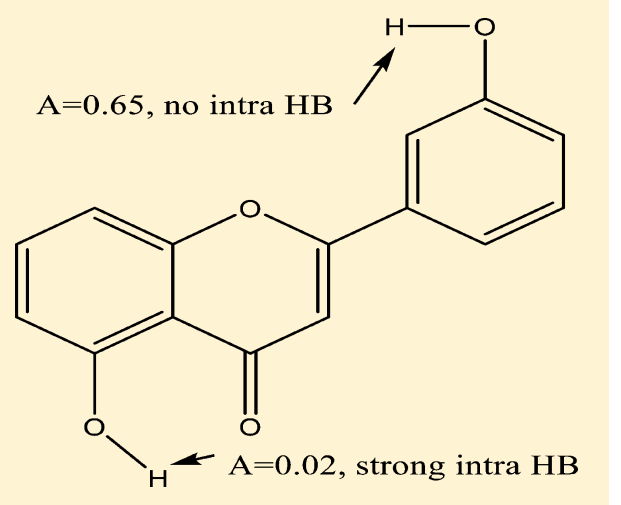

\section{INTRODUCTION}

Shalaeva et al. ${ }^{1}$ have recently shown that the presence of an intramolecular hydrogen bond (intraHB) in a molecule can considerably alter the properties of a molecule. These include properties relevant to drug design such as solubility, permeability, and partition. It is therefore important to be able to identify molecules that possess intraHBs and, if possible, to assess the effect of an intraHB on the molecular properties. Testa and co-workers ${ }^{2-5}$ were the first to show that the effect of intraHBs could be observed in water-solvent partition coefficients $(\operatorname{as} \log P)$ and particularly in differences between partition coefficients in water-octanol and water-aprotic solvent systems. They set out differences in $\log P$ for wateroctanol and water-heptane partitions (eq 1) and showed that intraHBs greatly reduce the value of $\Delta(\log P)_{\text {oct-hept }}$. They also observed similar effects due to intraHBs in other water-octanol and water-solvent systems. ${ }^{4,5}$ Leo ${ }^{6}$ used octanol and chloroform as the two solvent systems in order to calculate the hydrogen bond acidity of a solute, and Feng et al. ${ }^{7}$ used dibutyl ether and cyclohexane as the solvent systems to calculate solute hydrogen bond acidity.

$$
\Delta(\log P)_{\text {oct-hept }}=\log P_{\text {oct }}-\log P_{\text {hept }}
$$

Testa and co-workers ${ }^{4,5}$ employed a linear free energy relationship (LFER) to show more exactly the factors contributing to $\Delta(\log P)$. A more up-to-date LFER is that due to Abraham and co-workers, ${ }^{8-10}$ shown as eq 2 . In this equation, $E$ is the solute excess molar refractivity in units of $\left(\mathrm{cm}^{3} \mathrm{~mol}^{-1}\right) / 10 ; S$ is the solute dipolarity/polarizability; $A$ and $B$ are the overall or summation hydrogen bond acidity and basicity, respectively; and $V$ is the McGowan characteristic volume in units of $\left(\mathrm{cm}^{3} \mathrm{~mol}^{-1}\right) / 100$. We shall not deal with the determination of the solute descriptors from experimental data, as this has been described several times in some detail (see refs 9 and 10 and especially the review by Clarke and Mallon ${ }^{11}$ ). The coefficients in eq 2 for $\log P$ values in a number of watersolvent systems ${ }^{12}$ are given in Table 1 . The differences in the coefficients reflect differences in $\log P$ and hence the values of $\Delta(\log P)$. For all of the aprotic solvents other than ethers and esters (which contain appreciable quantities of water in contact with water), the differences in the a coefficient from that in octanol are very large, and it is this difference that has led previous workers $^{2-7}$ to suggest that $\Delta(\log P)_{\text {oct-solvent }}$ can be

Received: September 9, 2014

Published: October 30, 2014 
Table 1. Coefficients in Equation 2 for Some Water-Solvent Partitions

\begin{tabular}{|c|c|c|c|c|c|c|}
\hline solvent & $c$ & $e$ & $s$ & $a$ & $b$ & $v$ \\
\hline octan-1-ol & 0.088 & 0.562 & -1.054 & 0.034 & -3.460 & 3.814 \\
\hline diethyl ether & 0.248 & 0.561 & -1.016 & -0.226 & -4.553 & 4.075 \\
\hline dibutyl ether & 0.252 & 0.677 & -1.506 & -0.807 & -5.249 & 4.815 \\
\hline ethyl acetate & 0.441 & 0.591 & -0.699 & -0.325 & -4.261 & 3.726 \\
\hline dichloromethane & 0.319 & 0.102 & -0.187 & -3.058 & -4.090 & 4.324 \\
\hline trichloromethane & 0.191 & 0.105 & -0.403 & -3.112 & -3.514 & 4.395 \\
\hline tetrachloromethane & 0.199 & 0.523 & -1.159 & -3.560 & -4.594 & 4.618 \\
\hline 1,2-dichloroethane & 0.183 & 0.294 & -0.134 & -2.801 & -4.291 & 4.180 \\
\hline hexane & 0.333 & 0.560 & -1.710 & -3.578 & -4.939 & 4.463 \\
\hline heptane & 0.297 & 0.634 & -1.755 & -3.571 & -4.946 & 4.488 \\
\hline octane & 0.241 & 0.690 & -1.769 & -3.545 & -5.011 & 4.511 \\
\hline hexadecane & 0.087 & 0.667 & -1.617 & -3.587 & -4.869 & 4.433 \\
\hline cyclohexane & 0.159 & 0.784 & -1.678 & -3.740 & -4.929 & 4.577 \\
\hline benzene & 0.142 & 0.464 & -0.588 & -3.099 & -4.625 & 4.491 \\
\hline toluene & 0.125 & 0.431 & -0.644 & -3.002 & -4.748 & 4.524 \\
\hline chlorobenzene & 0.065 & 0.381 & -0.521 & -3.183 & -4.700 & 4.614 \\
\hline nitrobenzene & -0.152 & 0.525 & 0.081 & -2.332 & -4.494 & 4.187 \\
\hline
\end{tabular}

used as a measure of the hydrogen bond acidity of a molecule. Then, as shown in Table 1 , intraHBs lead to a reduction in the overall hydrogen bond acidity of a molecule and hence to an increase in $\Delta(\log P)_{\text {oct-solvent }}$ by comparison to a "control" molecule in which there is no intraHB. As mentioned above, Feng et al. ${ }^{7}$ used the difference in $\log P$ values in dibutyl ether and cyclohexane to calculate the solute hydrogen bond acidity. It can be seen from Table 1 that the difference between the $a$ coefficients for these two systems is also very large.

$$
\log P=c+e E+s S+a A+b B+v V
$$

Shalaeva et al. ${ }^{1}$ used these concepts to investigate values of $\Delta(\log P)$ derived from water-octanol and water-toluene partitions as an indicator of intraHBs. They measured $\log P$ values in the two given systems for a "test" compound and a "control" compound and suggested that if $\Delta(\log P)_{\text {oct-tol }}$ (test) $<\Delta(\log P)_{\text {oct-tol }}($ control $)$ then the test compound has a high propensity to form an intraHB, whereas if $\Delta(\log P)_{\text {oct-tol }}$ (test) $>\Delta(\log P)_{\text {oct-tol }}($ control $)$ the test compound has a low propensity to form an intraHB. They gave a number of illustrations involving the intraHB between an $\mathrm{NH}$ hydrogen and an amide $\mathrm{C}=\mathrm{O}$ group in which the intraHB was usually part of a six-membered-ring system. The experimental work is considerable, as it requires the determination of water-octanol and water-toluene partition coefficients for the test molecule and the control molecule, that is, four separate partition measurements. However, Shalaeva et al. ${ }^{1}$ pointed out that the four partition coefficients could be calculated using COSMO$\mathrm{RS}^{13}$ in which case no experimental measurements were needed at all. They suggested that COSMO-RS was the only method available for the computation of $\log P$ values in solvents other than octanol, but the SPARC method $^{14}$ can be used to compute $\log P$ values in almost any water-solvent system.

Whether $\Delta(\log P)_{\text {oct-tol }}$ is obtained by experiment or calculation, it suffers from some disadvantages as a method of indicating the presence or absence of intraHBs. $\Delta(\log P)_{\text {oct-tol }}$ is an approximation to the overall hydrogen bond acidity of a molecule, $A$, and does not relate to any specific acidic group in a molecule. It is only a measure of the hydrogen bond acidity of a particular $\mathrm{NH}$ group if this is the sole acidic group in the molecule. In addition, to date the method only separates solutes into those that may and those that may not form an intraHB.
In a later paper, Goetz et al. ${ }^{15}$ described another indirect method for the detection of intraHBs that is based on chromatographic retention times of a test compound and a control compound that was designed to have no intraHB in a supercritical fluid chromatographic system. If the retention time of the test compound was lower than that of the control compound, this indicated that the test compound had an intraHB. Goetz et al. ${ }^{15}$ also used the temperature variation of the $\mathrm{NH}$ chemical shifts in DMSO as a corroboration of the assignment. It was suggested that the temperature variation for amides with an intraHB is less negative than that for amides with no intraHB. Several examples of the detection of intraHBs were given. With one exception, all of the examples were of intraHBs formed by $\mathrm{NH}$ acidic groups.

Abraham et al. ${ }^{16}$ described how values of the $A$ descriptor for a given solute can be obtained from the solute NMR shifts in DMSO and chloroform. Whaley et al. ${ }^{17}$ then applied the NMR method to the determination of $A$ values for $\mathrm{OH}$ groups in a number of mono- and dihydroxyflavones (see Figure 1). These<smiles>O=c1cc(-c2ccccc2)oc2ccccc12</smiles>

Figure 1. Flavone.

$A$ values are the key to intramolecular hydrogen bonding. If an intraHB is formed by a given $\mathrm{OH}$ or $\mathrm{NH}$ group, then the $A$ value of that group will be diminished because the propensity to form an intermolecular hydrogen bond will be reduced. Thus, the measurement of an $A$ value for a particular $\mathrm{OH}$ or $\mathrm{NH}$ group will provide a quantitative estimate of the extent of intraHB due to that particular group. It is our intention to use the NMR method ${ }^{16}$ to evaluate intraHBs for a variety of compounds that possess $\mathrm{OH}$ or $\mathrm{NH}$ acidic groups and then to relate intraHBs to actual values for some important properties. We denote $A$ values determined by the NMR method as $A_{\mathrm{NMR}}$ 
Table 2. Differences in Chemical Shift, $\Delta \delta(\mathrm{OH})$, and Corresponding $A_{\mathrm{NMR}}$ Values for OH Groups in Mono- and Dihydroxy Compounds

\begin{tabular}{|c|c|c|c|c|c|c|}
\hline \multirow[b]{2}{*}{ compound } & \multicolumn{2}{|c|}{$\delta$} & \multirow[b]{2}{*}{$\Delta \delta(\mathrm{OH})$} & \multirow[b]{2}{*}{$A_{\mathrm{NMR}}$} & \multirow[b]{2}{*}{ intraHB } & \multirow[b]{2}{*}{ ref } \\
\hline & DMSO & $\mathrm{CDCl}_{3}$ & & & & \\
\hline phenol & 9.29 & 4.69 & 4.60 & 0.62 & none & 21 \\
\hline 2-cyanophenol & & & 5.36 & 0.72 & none & 16,22 \\
\hline 4-cyanophenol & & & 5.31 & 0.71 & none & 16,22 \\
\hline 2-nitrophenol & & & 0.33 & 0.05 & strong & 16,22 \\
\hline 4-nitrophenol & & & 5.64 & 0.76 & none & 16,22 \\
\hline 2-methoxyphenol & 8.91 & 5.75 & 3.15 & 0.43 & weak & $a$ \\
\hline 4-aminobenzyl alcohol & 5.00 & 2.12 & 2.88 & 0.39 & none & 16,23 \\
\hline 4-aminophenol & 8.36 & 4.20 & 4.16 & 0.56 & none & 16,23 \\
\hline 3-hydroxyflavone & 9.62 & 7.00 & 2.62 & 0.35 & weak & 17 \\
\hline 5-hydroxyflavone & 12.67 & 12.56 & 0.11 & 0.02 & strong & 17 \\
\hline 6-hydroxyflavone & 9.96 & 5.44 & 4.51 & 0.61 & none & 17 \\
\hline 7-hydroxyflavone & 10.83 & 5.81 & 5.02 & 0.67 & none & 17 \\
\hline $2^{\prime}$-hydroxyflavone & & & 3.02 & 0.41 & weak & 17 \\
\hline $3^{\prime}$-hydroxyflavone & & & 4.86 & 0.65 & none & 17 \\
\hline $4^{\prime}$-hydroxyflavone & & & 3.96 & 0.53 & none & 17 \\
\hline $4^{\prime}$-hydroxy-3'-methoxyflavone & 9.91 & 5.95 & 3.96 & 0.53 & none & 17 \\
\hline 8-hydroxy-7-methoxyflavone & 9.72 & 5.72 & 4.00 & 0.54 & none & 17 \\
\hline methanol & 4.05 & 0.85 & 3.20 & 0.43 & none & 21 \\
\hline ethanol & 4.31 & 1.10 & 3.21 & 0.43 & none & 21 \\
\hline propanol & 4.31 & 1.22 & 3.09 & 0.42 & none & 21 \\
\hline butanol & 4.30 & 1.17 & 3.13 & 0.42 & none & 21 \\
\hline propan-2-ol & 4.30 & 1.23 & 3.07 & 0.41 & none & 21 \\
\hline trans-4-tert-butylcyclo hexanol & 4.39 & 1.40 & 2.99 & 0.40 & none & 21 \\
\hline cis-4-tert-butylcyclohexanol & 4.11 & 1.40 & 2.77 & 0.38 & none & 21 \\
\hline 1-HO-2,2-diMes-ethene ${ }^{b}$ & 9.01 & 4.66 & 4.35 & 0.59 & none & 24 \\
\hline 1-HO-1,2,3-triMes-ethene & 8.34 & 5.20 & 3.14 & 0.42 & none & 24 \\
\hline 1-HO-1-phenyl-2,2-diMes-ethene & 8.51 & 5.17 & 3.34 & 0.45 & none & 24 \\
\hline 1-HO-1-9-anthryl-2,2-diMes-ethene & 9.19 & 5.70 & 3.49 & 0.47 & none & 24 \\
\hline 1-HO-1,2-diMes-2-phenylethene & 8.29 & 4.72 & 3.57 & 0.48 & none & 24 \\
\hline 4-hydroxy-4-methylpent-2-one & 4.57 & 3.79 & 0.78 & 0.11 & medium & $a$ \\
\hline 2-dimethylaminoethanol & 4.37 & 3.11 & 1.26 & 0.17 & medium & $a$ \\
\hline benzoic acid & 12.96 & 12.45 & 0.51 & 0.07 & see text & $a$ \\
\hline cinnamic acid & 12.42 & 12.17 & 0.25 & 0.04 & see text & $a$ \\
\hline acetylsalicylic acid & 12.02 & 13.12 & -1.10 & -0.14 & see text & $a$ \\
\hline chromone-3-carboxylic acid & 13.26 & 13.43 & -0.17 & -0.02 & see text & $a$ \\
\hline coumarin-3-carboxylic acid & 13.31 & 12.27 & 1.04 & 0.14 & see text & $a$ \\
\hline mefenamic acid & 13.01 & 11.64 & 1.37 & 0.19 & see text & $a$ \\
\hline catechol & 8.83 & 5.31 & 3.52 & 0.47 & see text & $a$ \\
\hline resorcinol & 8.92 & 4.51 & 4.41 & 0.59 & see text & 16,23 \\
\hline hydroquinone & 8.63 & 4.43 & 4.20 & 0.57 & see text & 16,23 \\
\hline 4-methylcatechol ( $p$-Me/OH) & 8.57 & 4.88 & 3.69 & 0.50 & see text & 18 \\
\hline 4-methylcatechol (m-Me/OH) & 8.71 & 5.02 & 3.69 & 0.50 & see text & 18 \\
\hline 5,7-dihydroxyflavone & & & $0.20(5)$ & 0.03 & strong $(5-\mathrm{OH})$ & 17 \\
\hline 5,7-dihydroxyflavone & & & $5.67(7)$ & 0.76 & none $(7-\mathrm{OH})$ & 17 \\
\hline $5,3^{\prime}$-dihydroxyflavone & & & $0.13(5)$ & 0.02 & strong $(5-\mathrm{OH})$ & 17 \\
\hline $5,3^{\prime}$-dihydroxyflavone & & & $5.02\left(3^{\prime}\right)$ & 0.67 & none $\left(3^{\prime}-\mathrm{OH}\right)$ & 17 \\
\hline 5,4'-dihydroxyflavone & & & $0.18(5)$ & 0.03 & strong $(5-\mathrm{OH})$ & 17 \\
\hline $5,4^{\prime}$-dihydroxyflavone & & & $5.43\left(4^{\prime}\right)$ & 0.73 & none $\left(4^{\prime}-\mathrm{OH}\right)$ & 17 \\
\hline \multirow[t]{2}{*}{ 5,4'-dihydroxy-7-methoxyflavone } & 12.95 & 12.93 & $0.02(5)$ & 0.01 & strong $(5-\mathrm{OH})$ & 18 \\
\hline & 10.56 & 5.36 & $5.20\left(4^{\prime}\right)$ & 0.70 & none $\left(4^{\prime}-\mathrm{OH}\right)$ & 18 \\
\hline ethane-1,2-diol & 4.47 & 1.78 & 2.69 & $(0.72)$ & see text & 21 \\
\hline propane-1,3- diol & 4.32 & 1.89 & 2.43 & $(0.66)$ & see text & 21 \\
\hline butane-1,4-diol & 4.38 & 1.83 & 2.55 & $(0.70)$ & see text & 21 \\
\hline pentane-1,5-diol & 4.34 & 1.24 & 3.10 & $(0.84)$ & see text & 21 \\
\hline trans-cyclohexane-1,2-diol & 4.42 & 2.07 & 2.35 & $(0.64)$ & see text & 21 \\
\hline trans-cyclohexane-1,4-diol & 4.38 & 1.55 & 2.83 & $(0.76)$ & see text & 21 \\
\hline cis-cyclohexane-1,4-diol & 4.25 & 1.55 & 2.70 & $(0.74)$ & see text & 21 \\
\hline
\end{tabular}

${ }^{a}$ This work, University College London. ${ }^{b}$ Mes = mesityl (2,4,6-trimethylphenyl). 
values in order to distinguish them from the Abraham $A$ values in eq $2 .^{8-11}$

\section{RESULTS}

Previous studies of ${ }^{1} \mathrm{H}$ NMR chemical shifts in chloroform and DMSO yielded the differences in the chemical shifts in the two solvents, $\Delta \delta$, for $\mathrm{OH}$ and $\mathrm{NH}$ groups in a large number of solutes: ${ }^{16-25}$

$$
\Delta \delta=\delta(\mathrm{DMSO})-\delta\left(\mathrm{CDCl}_{3}\right)
$$

This difference is related to the hydrogen bond acidity of the $\mathrm{OH}$ or $\mathrm{NH}$ group through eq $4:^{16}$

$$
A_{\mathrm{NMR}}=0.0065+0.133 \Delta \delta
$$

Values of the differences for $\mathrm{OH}$ groups, $\Delta \delta(\mathrm{OH})$, are given for monohydroxy compounds in Table 2 , together with the $A_{\mathrm{NMR}}$ values calculated using eq 4 . There is a clear distinction between aromatic $\mathrm{OH}$ groups that do not form an intraHB, which have $A_{\mathrm{NMR}}>0.5$, and $\mathrm{OH}$ groups that form a strong intraHB, which have $A_{\mathrm{NMR}}<0.1$. An example of a very strong intraHB is found in 2-nitrophenol, where a six-membered intramolecular ring is formed between the hydroxyl and nitro groups. 2-Methoxyphenol, with $A_{\mathrm{NMR}}=0.43$, appears to form a weak intraHB through a five-membered-ring system. In a very important development, Whaley et al. ${ }^{17}$ used the NMR method $^{16}$ to identify intraHBs in a number of hydroxyflavones (Figure 1). A very strong intraHB is found in the case of 5hydroxyflavone, which involves the formation of a sixmembered intramolecular ring between the 5-hydroxy group and the flavone carbonyl group. The 3-hydroxy group can also form an intraHB with the flavone carbonyl group, but this involves a five-membered intramolecular ring, and the intraHB is much weaker. Perhaps surprisingly, a weak intraHB is formed by the $2^{\prime}$-hydroxy group, which has $A_{\mathrm{NMR}}=0.41$, quite a bit lower than that of phenol. Inspection of the structure of $2^{\prime}$ hydroxyflavone shows that a six-membered intramolecular ring can be formed between the 2 -hydroxy group and the flavone ether oxygen.

Aliphatic $\mathrm{OH}$ groups in alkanols have intrinsically lower $A$ values than aromatic phenolic $\mathrm{OH}$ groups, so the qualification for an intraHB involving an aliphatic $\mathrm{OH}$ is also lower. We suggest that for aliphatic alkanol $\mathrm{OH}$ groups, if $A_{\mathrm{NMR}}>0.3$ there is no intraHB and if $A_{\mathrm{NMR}}<0.1$ an intraHB is present. A number of enols are all more acidic than simple aliphatic alcohols, ${ }^{24}$ but the $-\mathrm{OH}$ in these enols must have some phenolic character.

We also studied a number of carboxylic acids (Table 2). There is an obvious difficulty in that carboxylic acids form dimers in nonpolar solvents such as chloroform. The $\mathrm{OH}$ signals for benzoic acid and cinnamic acid in deuterochloroform are quite broad, possibly because of exchange between the dimer and monomer, and the $A_{\mathrm{NMR}}$ values of 0.07 and 0.04 strongly indicate that these acids exist in deuterochloroform mainly in the dimeric form. Aspirin (acetylsalicylic acid) has an $A_{\mathrm{NMR}}$ value of -0.14 (Table 2 ). This is an interesting solute because it could form a six-membered intraHB involving the carboxylic $\mathrm{OH}$ group and the ether oxygen in the $\mathrm{OC}(=\mathrm{O}) \mathrm{Me}$ entity or it could form an eight-membered intraHB with the carbonyl oxygen in $\mathrm{OC}(=\mathrm{O}) \mathrm{Me}$. A single-molecule gas-phase calculation using the MMX force field (as implemented in the software package PCModel ${ }^{26}$ ) suggests that the six-membered intraHB is preferred, but this is only a weak intraHB, as shown by the value $A=0.45$ for 2 -methoxybenzoic acid. ${ }^{27}$ The ether oxygen in aspirin is even less basic than the ether oxygen in 2methoxybenzoic acid, so we expect $A$ for aspirin to be larger than $A$ for 2-methoxybenzoic acid. In the event, $A=0.71$ for aspirin, ${ }^{27}$ suggesting that there is no intraHB at all. Therefore, the very small $A_{\mathrm{NMR}}$ value for aspirin, -0.14 , must also arise through dimerization. Both chromone-3-carboxylic acid and coumarin-3-carboxylic acid can form a six-membered intraHB; their $A_{\mathrm{NMR}}$ values are -0.02 and 0.14 respectively. Mefenamic acid can form a six-membered intraHB between the $\mathrm{CO}_{2} \mathrm{H}$ group and an $\mathrm{NH}$ nitrogen, either with the structure $\mathrm{O}-\mathrm{H} \cdots \mathrm{N}$ or $\mathrm{C}=\mathrm{O} \cdots \mathrm{HN}$. The $A_{\mathrm{NMR}}$ value for the $\mathrm{OH}$ group is 0.19 , which suggests either an intraHB with the structure $\mathrm{O}-\mathrm{H} \cdots \mathrm{N}$ or dimerization. Thus, for all three of these acids the $A_{\mathrm{NMR}}$ value is commensurate with either formation of an intraHB or dimerization. It seems clear that little can be deduced about intramolecular hydrogen bonding involving carboxylic acids from our NMR shifts because of the strong tendency of the acids to dimerize in deuterochloroform.

Table 2 also provides data on chemical shifts for dihydroxy compounds. For the aliphatic dihydroxy compounds, normally there is exchange on the NMR time scale between the two $\mathrm{OH}$ groups in a molecule. Thus, for compounds such as ethane-1,2diol and pentane-1,5-diol there is only one $\mathrm{OH}$ signal in chloroform and one $\mathrm{OH}$ signal in DMSO. The chemical shift corresponding to these signals is an average of the chemical shifts of the two $\mathrm{OH}$ groups, and hence any calculated $A_{\mathrm{NMR}}$ value from eq 4 is also an average $A$ value for the two $\mathrm{OH}$ groups. Then the overall $A_{\mathrm{NMR}}$ value can be taken as twice the $A_{\mathrm{NMR}}$ value calculated from eq 4 . For symmetrical compounds such as resorcinol and hydroquinone, the observed single $\mathrm{OH}$ shift could due to exchange or simply that the two $\mathrm{OH}$ groups have the same NMR shift. The result of Siskos et al. ${ }^{18}$ for 4methylcatechol, in which the two $\mathrm{OH}$ groups are not equivalent, suggests that in resorcinol and hydroquinone the single observed shift is due to the equivalence of the $\mathrm{OH}$ groups. Then the overall $A_{\mathrm{NMR}}$ values for catechol, resorcinol, and hydroquinone are $0.94,1.18$ and 1.14 , respectively, so on the basis of the NMR results it is possible that catechol forms a weak intraHB. The corresponding overall $A$ values from eq 2 are $0.88,1.09$, and $1.06,{ }^{27}$ which again supports a weak intraHB in catechol.

A comparison of the $A_{\mathrm{NMR}}$ values with the overall $A$ values from eq 2 can be made for nine dihydroxy compounds in Table 2. The average deviation between the two sets is 0.04 , and the standard deviation is 0.11 units. The NMR method is thus capable of obtaining $A$ values for these dihydroxy compounds to within about 0.10 unit. It is difficult to reach any conclusion for the alkanediols. The $A$ value from eq 2 for alkan-1-ols is 0.37 , and therefore, in the absence of possible electronic effects, an $A$ value of 0.74 for an alkanediol would suggest that no intraHB is formed, as indicated by the $A_{\mathrm{NMR}}$ values. The $A$ value of 0.33 from eq 2 for an alkan-2-ol is rather less, so $A_{\mathrm{NMR}}$ values of $0.64-0.76$ for the cyclohexanediols again suggest that no intraHB is formed.

We have included in Table 2 important data on a number of dihydroxyflavones obtained by Whaley et al., ${ }^{17}$ in which one substituent is the 5-hydroxy group. Unlike the dihydroxybenzenes and dihydroxyalcohols, these flavones gave two distinct signals, one for the 5-hydroxy substituent and one for the other hydroxyl substituent. The chemical shifts for 5-hydroxyflavone itself (Table 2) indicate that the $A_{\mathrm{NMR}}$ value for this compound is only 0.02 and hence that 5-hydroxyflavone forms a very strong intraHB involving a six-membered ring with the flavone 
Table 3. Chemical Shifts, $\delta$, in DMSO and Chloroform, Their Differences $\Delta \delta(\mathrm{NH})$, and $A_{\mathrm{NMR}}$ Values for Some NH Groups

\begin{tabular}{|c|c|c|c|c|c|c|}
\hline \multirow[b]{2}{*}{ compound } & \multicolumn{2}{|c|}{$\delta$} & \multirow[b]{2}{*}{$\Delta \delta(\mathrm{NH})$} & \multirow[b]{2}{*}{$A_{\mathrm{NMR}}$} & \multirow[b]{2}{*}{ IntraHB } & \multirow[b]{2}{*}{ ref } \\
\hline & DMSO & $\mathrm{CDCl}_{3}$ & & & & \\
\hline formamide $\left(\mathrm{H}_{\mathrm{b}}\right)$ & 7.41 & 5.48 & 1.93 & 0.26 & none & 21 \\
\hline formamide $\left(\mathrm{H}_{\mathrm{a}}\right)$ & 7.14 & 5.80 & 1.34 & 0.18 & & 21 \\
\hline $\mathrm{N}$-methylformamide $\left(\mathrm{H}_{\mathrm{b}}\right)$ & 7.90 & 5.55 & 2.35 & 0.28 & none & 21 \\
\hline$N$-methylformamide $\left(\mathrm{H}_{\mathrm{a}}\right)$ & 7.90 & 5.86 & 2.04 & 0.28 & & 21 \\
\hline acetamide $\left(\mathrm{H}_{\mathrm{b}}\right)$ & 7.30 & 5.42 & 1.88 & 0.26 & none & 21 \\
\hline acetamide $\left(\mathrm{H}_{\mathrm{a}}\right)$ & 6.70 & 5.42 & 1.29 & 0.18 & & 21 \\
\hline trimethylacetamide $\left(\mathrm{H}_{\mathrm{b}}\right)$ & 6.97 & 5.22 & 1.75 & 0.24 & none & 21 \\
\hline trimethylacetamide $\left(\mathrm{H}_{\mathrm{a}}\right)$ & 6.64 & 5.56 & 1.08 & 0.15 & & 21 \\
\hline$N$-methylacetamide $\left(\mathrm{H}_{\mathrm{b}}\right)$ & 7.70 & 5.53 & 2.17 & 0.30 & none & 21 \\
\hline proprionamide $\left(\mathrm{H}_{\mathrm{b}}\right)$ & 7.16 & 5.38 & 1.78 & 0.24 & none & 21 \\
\hline proprionamide $\left(\mathrm{H}_{\mathrm{a}}\right)$ & 6.62 & 6.14 & 0.48 & 0.07 & & 21 \\
\hline valerolactam & 7.34 & 6.33 & 1.01 & 0.14 & none & 21 \\
\hline caprolactam & 7.34 & 6.35 & 0.99 & 0.14 & none & 21 \\
\hline acetanilide & 9.94 & 7.79 & 2.15 & 0.29 & none & 19,20 \\
\hline 2,4,6-trimethylacetanilide $\left(\mathrm{H}_{\mathrm{b}}\right)$ & 9.20 & 6.66 & 2.54 & 0.34 & none & 21 \\
\hline 2,4,6-trimethylacetanilide $\left(\mathrm{H}_{\mathrm{a}}\right)$ & & 6.58 & & & & 19,20 \\
\hline benzamide $\left(\mathrm{H}_{\mathrm{b}}\right)$ & 7.93 & 6.08 & 1.85 & 0.25 & none & 19,20 \\
\hline benzamide $\left(\mathrm{H}_{\mathrm{a}}\right)$ & 7.34 & 6.08 & 1.26 & 0.17 & & 21 \\
\hline 2,4,6-trimethylbenzamide $\left(\mathrm{H}_{\mathrm{b}}\right)$ & 7.59 & 5.74 & 1.85 & 0.25 & none & 21 \\
\hline 2,4,6-trimethylbenzamide $\left(\mathrm{H}_{\mathrm{a}}\right)$ & 7.34 & 6.22 & 1.12 & 0.16 & & 21 \\
\hline 2-fluorobenzamide $\left(\mathrm{H}_{\mathrm{b}}\right)$ & 7.59 & 6.09 & 1.50 & 0.21 & none & 21 \\
\hline 2-fluorobenzamide $\left(\mathrm{H}_{\mathrm{a}}\right)$ & 7.66 & 6.72 & 0.94 & 0.13 & & 21 \\
\hline 2-chlorobenzamide $\left(\mathrm{H}_{\mathrm{b}}\right)$ & 7.87 & 6.40 & 1.47 & 0.20 & none & $a$ \\
\hline 2-chlorobenzamide $\left(\mathrm{H}_{\mathrm{a}}\right)$ & 7.58 & 6.40 & 1.18 & 0.16 & & $a$ \\
\hline 2-ethoxybenzamide $\left(\mathrm{H}_{\mathrm{b}}\right)$ & 7.63 & 7.91 & -0.28 & -0.03 & strong & $a$ \\
\hline 2-ethoxybenzamide $\left(\mathrm{H}_{\mathrm{a}}\right)$ & 7.60 & 7.15 & 0.45 & 0.07 & & $a$ \\
\hline formanilide $\left(\mathrm{H}_{\mathrm{b}}\right)$ & 10.19 & 7.14 & 3.05 & 0.41 & none & 21 \\
\hline formanilide $\left(\mathrm{H}_{\mathrm{a}}\right)$ & 10.14 & 8.34 & 1.80 & 0.25 & & 21 \\
\hline 4-aminopent-3-en-2-one $\left(\mathrm{H}_{\mathrm{b}}\right)$ & 9.46 & 9.71 & -0.26 & -0.03 & strong & $b$ \\
\hline 4-aminopent-3-en-2-one $\left(\mathrm{H}_{\mathrm{a}}\right)$ & 7.43 & 4.95 & 2.48 & 0.34 & & $b$ \\
\hline 2-pyrrolidinone & 7.46 & 6.06 & 1.40 & 0.19 & none & 19,20 \\
\hline phenanthridone & 11.65 & 9.17 & 2.48 & 0.34 & none & 21 \\
\hline diphenylamine & 8.10 & 5.68 & 2.42 & 0.33 & none & 15,23 \\
\hline benzotriazole & 14.00 & 10.20 & 3.80 & 0.51 & none & 15,23 \\
\hline aniline & 4.94 & 3.61 & 1.33 & 0.18 & none & 21 \\
\hline$o$-phenylenediamine & 4.38 & 3.38 & 1.00 & 0.14 & none & $b$ \\
\hline$p$-phenylenediamine & 4.18 & 3.33 & 0.85 & 0.12 & none & $b$ \\
\hline 2-nitroaniline & 7.41 & 6.12 & 1.29 & 0.18 & none & $b$ \\
\hline 2-aminoacetanilide $(\mathrm{NH})$ & 4.85 & 3.85 & 1.00 & 0.14 & none & $b$ \\
\hline 2-aminoacetanilide (NHCO) & 9.12 & 7.29 & 1.83 & 0.25 & none & $b$ \\
\hline$N$-methylaniline & 5.52 & 3.66 & 1.86 & 0.25 & none & 21 \\
\hline$N$-phenylaniline & 8.10 & 5.68 & 2.42 & 0.33 & none & 21 \\
\hline 4-aminophenol & 4.36 & 3.22 & 1.13 & 0.16 & none & 16,23 \\
\hline 4-aminobenzyl alcohol & 4.96 & 3.74 & 1.22 & 0.17 & none & 16,23 \\
\hline$p$-toluenesulfonamide & 7.29 & 4.70 & 2.59 & 0.35 & none & 16,23 \\
\hline trans- $\mathrm{N}$-acetyl-4-tert-butylcyclohexylamine & 7.66 & 5.56 & 2.11 & 0.29 & none & 21 \\
\hline cis- $N$-acetyl-4-tert-butylcyclohexylamine & 7.61 & 5.42 & 2.19 & 0.30 & none & 21 \\
\hline pentylamine & 1.22 & 1.00 & 0.22 & 0.04 & see text & 21 \\
\hline diethylamine & 1.29 & 0.80 & 0.49 & 0.07 & see text & 21 \\
\hline $\mathrm{PhC}(=\mathrm{O}) \mathrm{N}(\mathrm{Et}) \mathrm{C}(=\mathrm{O}) \mathrm{NHPh}$ & 10.04 & 11.33 & -1.29 & -0.17 & strong & 25 \\
\hline $\mathrm{PhC}(=\mathrm{O}) \mathrm{N}(\mathrm{Et}) \mathrm{C}(=\mathrm{O}) \mathrm{NHMe}$ & 8.11 & 8.97 & -0.86 & -0.11 & strong & 25 \\
\hline $\mathrm{PhC}(=\mathrm{O}) \mathrm{N}(\mathrm{Et}) \mathrm{C}(=\mathrm{O}) \mathrm{NH}^{i} \mathrm{Pr}$ & 7.93 & 8.83 & -0.90 & -0.11 & strong & 25 \\
\hline $\mathrm{PhC}(=\mathrm{O}) \mathrm{N}(\mathrm{Et}) \mathrm{C}(=\mathrm{O}) \mathrm{NH}-{ }^{t} \mathrm{Bu}$ & 7.84 & 8.90 & -1.06 & -0.13 & strong & 25 \\
\hline $\mathrm{PhC}(=\mathrm{O}) \mathrm{N}\left({ }^{i} \operatorname{Pr}\right) \mathrm{C}(=\mathrm{O}) \mathrm{NHPh}$ & 9.93 & 10.30 & -0.37 & -0.04 & strong & 25 \\
\hline $\mathrm{PhC}(=\mathrm{O}) \mathrm{N}\left({ }^{i} \mathrm{Pr}\right) \mathrm{C}(=\mathrm{O}) \mathrm{NHMe}$ & 7.82 & 7.76 & 0.06 & 0.01 & strong & 25 \\
\hline $\operatorname{PhC}(=\mathrm{O}) \mathrm{N}\left({ }^{i} \operatorname{Pr}\right) \mathrm{C}(=\mathrm{O}) \mathrm{NH}-{ }^{i} \mathrm{Pr}$ & 7.75 & 6.70 & 1.05 & 0.15 & weak & 25 \\
\hline $\operatorname{PhC}(=\mathrm{O}) \mathrm{N}\left({ }^{i} \operatorname{Pr}\right) \mathrm{C}(=\mathrm{O}) \mathrm{NH}-{ }^{t} \mathrm{Bu}$ & 7.58 & 6.19 & 1.61 & 0.22 & none & 25 \\
\hline acetanilide & 9.91 & 7.08 & 2.83 & 0.38 & none & 25 \\
\hline$N$-methylacetamide & 7.73 & 5.42 & 2.31 & 0.31 & none & 25 \\
\hline
\end{tabular}


Table 3. continued

\begin{tabular}{|c|c|c|c|c|c|c|}
\hline \multirow[b]{2}{*}{ compound } & \multicolumn{2}{|c|}{$\delta$} & \multirow[b]{2}{*}{$\Delta \delta(\mathrm{NH})$} & \multirow[b]{2}{*}{$A_{\mathrm{NMR}}$} & \multirow[b]{2}{*}{ IntraHB } & \multirow[b]{2}{*}{ ref } \\
\hline & DMSO & $\mathrm{CDCl}_{3}$ & & & & \\
\hline$N$-isopropylacetamide & 7.67 & 5.27 & 2.40 & 0.33 & none & 25 \\
\hline$N$-tert-butylacetamide & 7.41 & 5.29 & 2.12 & 0.29 & none & 25 \\
\hline compound 1 & 8.52 & 8.69 & -0.17 & -0.02 & strong & 1 \\
\hline compound 2 & 10.60 & 10.78 & -0.18 & -0.02 & strong & 1 \\
\hline compound 3 & 7.53 & 7.64 & -0.11 & -0.01 & strong & 1 \\
\hline compound 4 & 10.51 & 10.37 & 0.14 & 0.03 & strong & 1 \\
\hline compound 5 & 10.56 & 10.44 & 0.12 & 0.02 & strong & 1 \\
\hline compound 6 & 4.83 & 3.90 & 0.93 & 0.13 & weak & 1 \\
\hline compound 7 & 8.38 & 6.06 & 2.32 & 0.32 & none & 1 \\
\hline compound 8 & 5.03 & 3.68 & 1.35 & 0.19 & none & 1 \\
\hline compound 9 & 5.25 & 6.01 & 2.24 & 0.30 & none & 1 \\
\hline compound 10 & 4.45 & 3.30 & 1.15 & 0.16 & none & 1 \\
\hline fipronil & & & 3.17 & 0.43 & none & 11 \\
\hline imidacloprid & & & 0.79 & 0.11 & weak & 11 \\
\hline
\end{tabular}

carbonyl group. If an $\mathrm{OH}$ group forms a very strong intraHB, the energy required to break this intraHB may be large in comparison with the energy barrier for the exchange of two $\mathrm{OH}$ groups. Then no exchange takes place on the NMR time scale, and the two $\mathrm{OH}$ group shifts appear separately. Thus, in 5,7dihydroxyflavone, values of $A_{\mathrm{NMR}}$ can be obtained both for the 5-hydroxy group and the 7-hydroxy group. ${ }^{17}$ The 5-hydroxy group forms a strong intraHB, but the 7-hydroxy group, with $A_{\mathrm{NMR}}=0.76$, does not form an intraHB at all. Similar results were found with $5,3^{\prime}$ - and 5,4'-dihydroxyflavones. Siskos et al. ${ }^{18}$ confirmed the results of Whaley et al. ${ }^{17}$ for $5,4^{\prime}$-dihydroxy-7methoxyflavone (genkwanin), where separate signals are observed for the 4'- and 5-hydroxy substituents (see Table 2).

In previous work, ${ }^{16,19-21}$ we recorded $\Delta \delta$ for $\mathrm{NH}$ groups in a selection of compounds. In the case of primary amides and primary amines that form an intraHB through their $\mathrm{NH}$ group, the chemical shift of the $\mathrm{NH}$ that takes part in the intraHB is not the same as the chemical shift of the $\mathrm{NH}$ that does not take part in an intraHB. We denote the hydrogen atom that is involved in an intraHB as $\mathrm{H}_{\mathrm{b}}$ and the hydrogen atom that does not take part in an intraHB as $\mathrm{H}_{\mathrm{a}}$.

Table 3 presents values of $\Delta \delta(\mathrm{NH})$ and the deduced $A_{\mathrm{NMR}}$ values for a number of nitrogen compounds, ${ }^{16,19-21,23,25}$ including two agrochemicals, fipronil and imidacloprid (Figure 2). ${ }^{11}$ Shalaeva et al. ${ }^{1}$ also determined $\Delta \delta(\mathrm{NH})$ for several of the compounds they had studied using the $\Delta(\log P)_{\text {oct-tol }}$ method, but they did not make any use of the $\Delta \delta$ values. We include in Table 3 the $\Delta \delta(\mathrm{NH})$ values observed by Shalaeva et al. ${ }^{1}$ and

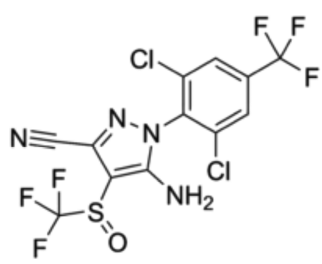

Fipronil

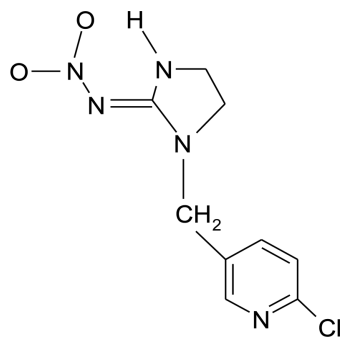

Imidacloprid the corresponding $A_{\mathrm{NMR}}$ values that we calculated using eq 4 . The structures of compounds $1-10$ in Table 3 are shown in Figure 3. The $\mathrm{NH}$ compounds in Table 3 represent a wide<smiles>CC(C)NC(=O)c1cc2ccccc2oc1=O</smiles>

1<smiles>CC(=O)NC(=O)Nc1ccccc1</smiles><smiles>[3H]c1ccc2ccccc2c1</smiles><smiles>CC(C)Nc1ccccc1NNc1ccccc1</smiles>

Figure 3. Compounds studied by Shalaeva et al. ${ }^{1}$ (see Table 3).<smiles>Cc1ccc(NC(=O)c2cc3ccccc3oc2=O)cc1</smiles>

2<smiles>CCC(=O)NC(=O)Nc1ccccc1</smiles><smiles>[B]Cc1ccccc1NC</smiles><smiles>CC(C)NC(=O)Nc1ccccc1</smiles>

selection of chemical structures, and for all of these compounds it is evident that $\Delta \delta(\mathrm{NH})$ and $A$ are functions of intramolecular hydrogen bonding. If $A_{\mathrm{NMR}}>0.15$ there is no intraHB, and if $A_{\mathrm{NMR}}<0.05$ there is a strong intraHB. Primary amines require special consideration. The two $\mathrm{NH}$ protons interconvert on the NMR time scale, so there is only one NH NMR signal in chloroform and in DMSO, and little can be deduced. Primary amides behave differently, and two signals are observed in chloroform and in DMSO, one from the $\mathrm{NH}$ cis to the $\mathrm{C}=\mathrm{O}$ group, $\mathrm{NH}_{a}$ and one from the $\mathrm{NH}$ trans to the $\mathrm{C}=\mathrm{O}$ group, $\mathrm{NH}_{\mathrm{b}}$. It is the $\mathrm{NH}_{\mathrm{b}}$ hydrogen that is normally involved in the intraHB. The very small $A_{\mathrm{NMR}}$ value of 0.03 for $\mathrm{NH}_{\mathrm{b}}$ shows that 2-ethoxybenzamide has a strong intraHB through a sixmembered ring. We can deduce that 2-chlorobenzamide $\left(A_{\mathrm{NMR}}=0.20\right)$ has no intraHB and that 2-fluorobenzamide

Figure 2. Fipronil and imidacloprid. 
Table 4. Differences in Chemical Shifts, $\Delta \delta(\mathrm{OH})$ and $\Delta \delta(\mathrm{NH})$, and the Corresponding $A_{\mathrm{NMR}}$ Values for OH and NH Groups in Compounds with Both $\mathrm{OH}$ and $\mathrm{NH}$ Groups

\begin{tabular}{|c|c|c|c|c|c|c|}
\hline \multirow[b]{2}{*}{ compound } & \multicolumn{2}{|c|}{$\delta$} & \multirow[b]{2}{*}{$\Delta \delta$} & \multirow[b]{2}{*}{$A_{\mathrm{NMR}}$} & \multirow[b]{2}{*}{ intraHB } & \multirow[b]{2}{*}{ ref } \\
\hline & DMSO & $\mathrm{CDCl}_{3}$ & & & & \\
\hline 2-aminoethanol (OH) & 4.45 & 2.28 & 2.17 & 0.30 & see text & $a$ \\
\hline 2-aminoethanol $\left(\mathrm{NH}_{2}\right)$ & 1.25 & 2.28 & -1.03 & -0.13 & see text & $a$ \\
\hline$N$-hydroxymethylnonanamide $(\mathrm{OH})$ & 5.53 & 3.39 & 2.14 & 0.29 & none & $a$ \\
\hline $\mathrm{N}$-hydroxymethylnonanamide $(\mathrm{NH})$ & 8.42 & 6.43 & 1.99 & 0.27 & none & $a$ \\
\hline
\end{tabular}

$\left(A_{\mathrm{NMR}}=0.14\right)$ possibly has a weak intraHB, again through a sixmembered-ring system. The two agrochemicals fipronil and imidacloprid ${ }^{11}$ are very interesting. Inspection of the structures shows that a six-membered intramolecular hydrogen bond is possible, in the case of fipronil with the sulfone $\mathrm{S}=\mathrm{O}$ group and in the case of imidacloprid with one of the $\mathrm{N}=\mathrm{O}$ groups in the $\mathrm{N}-\mathrm{N}(\mathrm{N}=\mathrm{O})_{2}$ substructure (see Figure 2). The NMR results show that fibronil $\left(A_{\mathrm{NMR}}=0.43\right)$ does not form an intraHB but that imidacloprid $\left(A_{\mathrm{NMR}}=0.11\right)$ may form a weak intraHB.

Lessene et al. ${ }^{25}$ studied a number of benzoylureas together with some test compounds; the chemical shifts are listed in Table 3. The NH group can form a six-membered ring with the benzoyl $\mathrm{C}=\mathrm{O}$ group, giving rise to an intraHB. It should be noted that the hydrogen bond acidity of the urea $\mathrm{C}(=$ O)NHPh group (eq $2, A=0.41)$ is larger than that in $\mathrm{C}(=$ O)NHMe (eq 2, $A=0.19$ ), which in turn is larger than that of a simple aliphatic amine $\mathrm{R}_{2} \mathrm{NH}$ (eq $2, A=0.08$ ). In addition there is a steric effect of alkyl groups, so the strength of the intraHB would be expected to change along the series $\mathrm{C}(=$ $\mathrm{O}) \mathrm{NHPh}>\mathrm{C}(=\mathrm{O}) \mathrm{NHMe}>\mathrm{C}(=\mathrm{O}) \mathrm{NH}^{i}{ }^{i} \mathrm{Pr}>\mathrm{C}(=$ $\mathrm{O}) \mathrm{NH}-{ }^{t} \mathrm{Bu}$, exactly as observed (Table 3 ). Indeed, the $A_{\mathrm{NMR}}$ value of 0.22 calculated for $\mathrm{PhC}(=\mathrm{O}) \mathrm{N}\left({ }^{i} \mathrm{Pr}\right) \mathrm{C}(=\mathrm{O}) \mathrm{NH}-{ }^{t} \mathrm{Bu}$ is so large that we deduce that there is no intraHB in this compound at all, whereas 1-benzoyl-1-ethyl-3-phenylurea, $\mathrm{PhC}(=\mathrm{O}) \mathrm{N}(\mathrm{Et}) \mathrm{C}(=\mathrm{O}) \mathrm{NHPh}$, has a very strong intraHB.

Simple aliphatic primary and secondary amines have very small values of $A$ from eq 2 ( 0.16 and 0.08 , respectively), ${ }^{27}$ so it is unlikely that intraHBs will form between an aliphatic amine (as an acid) and a hydrogen-bond base unless the latter is very strong. 4-Aminopent-3-en-2-one $\left(A_{\mathrm{NMR}}=-0.03\right)$ is an exception because the $\mathrm{C}=\mathrm{C}$ double bond confers extra acidity on the $\mathrm{NH}$ protons, which leads to a strong intraHB involving a six-membered ring with the $\mathrm{NH}$ and the carbonyl $\mathrm{C}=\mathrm{O}$ group. The difference between the $A$ values for aliphatic amines that do not form an intraHB ( 0.16 or 0.08$)$ and the $A$ values that arise from formation of a strong intraHB $(-0.03)$ is quite small, so for simple aliphatic amines it is difficult to decide whether an observed small value of $A_{\mathrm{NMR}}$ is due to formation of an intraHB.

A comparison between our conclusions and those of Shalaeva et al. ${ }^{1}$ can be made for compounds with available $\Delta \delta(\mathrm{NH})$ values. These are shown in Figure 3. Our assessments of intraHBs for these compounds are the same as those of Shalaeva et al., ${ }^{1}$ with a few exceptions. For compound 4, our unambiguous assessment is for a strong intraHB, but the $\Delta(\log P)$ value for compound 4 is so close to that for the control compound, for both the COSMO and shake-flask methods, that assignment of an intraHB on this basis is difficult. We also studied two compounds with both $\mathrm{OH}$ and $\mathrm{NH}$ groups (Table 4). In the case of 2-aminoethanol there is interchange between the $\mathrm{OH}$ and $\mathrm{NH}$ protons in chloroform, and little can be deduced. The compound $\mathrm{N}$-hydroxymethylnonanamide contains the $\mathrm{R}-\mathrm{C}(=\mathrm{O})-\mathrm{NH}-\mathrm{CH}_{2}-\mathrm{OH}$ substructure, and the $\mathrm{OH}$ and $\mathrm{NH}$ protons give rise to different chemical shifts in chloroform. These shifts indicate that an intraHB does not form between the $\mathrm{OH}$ group and the $\mathrm{C}=\mathrm{O}$ carbonyl group.

\section{DISCUSSION}

There are very clear advantages of the NMR method over the use of $\Delta(\log P)$ or chromatographic methods in the assessment of intraHBs. It is not necessary to have to devise a control compound to obtain information about the strength of an intraHB. This can be done simply from the NMR chemical shifts of the test compound. In favorable cases a specific intraHB can be identified even when there are two hydroxyl groups in the same compound. Finally, and very importantly, the method is practically very simple. A summary of the $A_{\mathrm{NMR}}$ values, obtained from $\Delta \delta(\mathrm{OH})$ and $\Delta \delta(\mathrm{NH})$, that are associated with intraHBs is given in Table 5 .

Table 5. Assessment of Intramolecular Hydrogen Bonding through Chemical Shifts and Values of the $A_{\mathrm{NMR}}$ Descriptor

$\begin{array}{clc}\text { hydrogen bond acid } & \text { intraHB } & \text { no intraHB } \\ \text { aromatic } \mathrm{OH} & A<0.1 & A>0.50 \\ \text { aliphatic } \mathrm{OH} & A<0.1 & A>0.30 \\ \mathrm{NH}^{a} & A<0.05 & A>0.15\end{array}$

${ }^{a}$ Excluding simple aliphatic amines.

The assessment of intraHB through some procedure such as our NMR chemical shift method, the partition coefficient method of Shalaeva et al., ${ }^{1}$ or the chromatographic method of Goetz et al. ${ }^{15}$ does not by itself lead to any estimate of the effect of intraHBs on physicochemical or biochemical properties. Neither Shalaeva et al. ${ }^{1}$ nor Goetz et al. ${ }^{15}$ addressed the problem of how intraHBs affect physicochemical or biochemical properties. However, this is a crucial step because it is the relationship between structural features such as intraHBs and biochemical and environmental properties that is a driving force in medicinal and environmental chemistry.

It is often assumed that intraHB will result in an increase of lipophilicity, ${ }^{1}$ that is, an increase in a water-solvent (usually water-octanol) partition coefficient. ${ }^{28}$ However, such an increase does not necessarily take place. We know that a strong indication of intraHB is the value of the $A$ descriptor, so the term $a A$ in eq 2 is crucial as regards the effect of intraHB on water-solvent partitions. Solvents such as octanol, diethyl ether, dibutyl ether, and ethyl acetate take up considerable quantities of water at saturation, and the resulting watersaturated solvent has about the same hydrogen bond basicity as water itself. This leads to very small values of the $a$ coefficient (see Table 1) and hence of the $a A$ term, so large changes in $A$ due to an intraHB lead to only small changes in the overall 
$\log P$ value. We can illustrate this by a comparison of the $\log P$ values for ethyl 2-hydroxybenzoate (ethyl salicylate) and ethyl 4-hydroxybenzoate (ethyl paraben). The descriptors for these two compounds are given in Table 6; the values of $A$ from eq 2

Table 6. Values of the Descriptors for Ethyl Salicylate and Ethyl Paraben

\begin{tabular}{|cccccc|}
\hline compound & $E$ & $S$ & $A$ & $B$ & $V$ \\
\hline ethyl salicylate & 0.802 & 0.91 & 0.03 & 0.43 & 1.2722 \\
ethyl paraben & 0.910 & 1.44 & 0.73 & 0.45 & 1.2722
\end{tabular}

are 0.03 and 0.73 , respectively, ${ }^{27}$ showing that ethyl salicylate possesses a very strong intraHB. Table 1 gives the equation coefficients for partitioning from water to a number of common solvents, and Table 7 provides equation coefficients for various permeation processes. Table 8 presents the effects of intraHBs on water-solvent partitions. The effect of intraHB on $\log P$ for water-octanol, water-diethyl ether, and water-ethyl acetate is quite small in contrast to the effect on $\log P$ for watertrichloromethane, water-heptane, and water-cyclohexane, exactly as expected. Thus, whether the intraHB leads to a substantial increase in lipophilicity depends on the actual definition of lipophilicity. We have not considered structural effects on water-octanol partitions, other than for the compounds in Table 6, because we are more concerned with the effects of intraHBs in general. In any case, structural effects on water-octanol partitions have been discussed in considerable detail already. ${ }^{29}$

Even more important is the effect of intraHB on biochemical and environmental processes. Table 7 gives equation coefficients for permeation of neutral molecules from water, for rat intestinal absorption, ${ }^{30}$ human intestinal absorption, ${ }^{30}$ permeation from saline through the brain barrier, ${ }^{31}$ permeation into cerasome, ${ }^{32}$ permeation through skin, ${ }^{33}$ and permeation into egg lecithin bilayers. ${ }^{30}$ We can use the equation coefficients in Table 7 and the descriptors in Table 6 to estimate the effect of intraHB on these permeation processes (Table 8). As in the case of water-solvent partition coefficients, the effect of intraHB depends crucially on the actual permeation process. The effect is very small for rat and human intestinal absorption, quite small for saline-brain permeation, skin permeation, and permeation into cerasome; and large for permeation into egg
Table 8. Effect of Intramolecular Hydrogen Bonding on Physicochemical, Biochemical, and Environmental Processes

\begin{tabular}{|c|c|c|c|}
\hline & $\begin{array}{c}\text { ethyl } \\
\text { salicylate }\end{array}$ & $\begin{array}{c}\text { ethyl } \\
\text { paraben }\end{array}$ & $\begin{array}{l}\text { effect of } \\
\text { intraHB }\end{array}$ \\
\hline \multicolumn{4}{|c|}{ Partitioning from Water $(\log P)$} \\
\hline octanol & 2.95 & 2.51 & 0.44 \\
\hline diethyl ether & $2.99^{b}$ & $2.27^{b}$ & 0.72 \\
\hline ethyl acetate & $3.18^{b}$ & $2.56^{b}$ & 0.62 \\
\hline dibutyl ether & $3.27^{b}$ & $1.87^{b}$ & 1.40 \\
\hline trichloromethane & 3.91 & 1.63 & 2.28 \\
\hline heptane & 2.63 & -0.90 & 3.53 \\
\hline cyclohexane & 2.80 & -0.64 & 3.44 \\
\hline \multicolumn{4}{|c|}{ Permeation from Water $(\log k)$} \\
\hline rat intestinal absorption & 0.925 & 0.725 & 0.20 \\
\hline human intestinal absorption & 0.596 & 0.391 & 0.21 \\
\hline brain permeation & -0.552 & -1.556 & 1.00 \\
\hline skin permeation & -4.451 & -4.985 & 0.53 \\
\hline permeation into cerasome & -0.726 & -1.143 & 0.42 \\
\hline egg lecithin bilayer & 2.588 & -0.207 & 2.80 \\
\hline$\% \mathrm{HIA}^{c}$ & 103 & 91 & 12 \\
\hline \multicolumn{4}{|c|}{ Environmental Processes } \\
\hline water to soil sorption & $2.477^{b}$ & $2.294^{b}$ & 0.18 \\
\hline water to Pahokee peat sorption & $2.133^{b}$ & $1.671^{b}$ & 0.46 \\
\hline water to poly(dimethylsiloxane) & $2.247^{b}$ & $-0.287^{b}$ & 2.53 \\
\hline water to poly(oxymethylene) & $2.264^{b}$ & $2.052^{b}$ & 0.21 \\
\hline water to the gas phase & $-2.2879^{b}$ & $-7.058^{b}$ & 4.77 \\
\hline
\end{tabular}

${ }^{a}$ Calculated as the value for ethyl salicylate minus the value for ethyl paraben. ${ }^{b}$ Estimated using the equation coefficients in Table 1. ${ }^{c}$ Human intestinal absorption expressed as the percentage of compound absorbed.

lecithin bilayers. Table 7 also gives equation coefficients for human intestinal absorption when the latter is expressed in the usual terms of \%HIA. The estimates of \%HIA in Table 8 (103 for ethyl salicylate and 91 for ethyl paraben) show in this particular case that constructing a molecule that has a strong intraHB in order to increase the \%HIA is of little value, as incorporation of an intraHB gives rise to only a small increase in \%HIA.

Table 7 also includes equation coefficients for some processes of environmental importance. A number of equations along the lines of eq 2 have been reported for sorption from water into soil, and we give the coefficients obtained by

Table 7. Coefficients in Equation 2 for Some Permeation and Environmental Processes

\begin{tabular}{|c|c|c|c|c|c|c|}
\hline & $c$ & $e$ & $s$ & $a$ & $b$ & $v$ \\
\hline \multicolumn{7}{|c|}{ Permeation Processes } \\
\hline rat intestinal absorption & 0.759 & 0.362 & -0.442 & 0.000 & -0.244 & 0.301 \\
\hline human intestinal absorption & 0.419 & 0.000 & 0.000 & -0.284 & -0.343 & 0.262 \\
\hline brain permeation & -1.268 & -0.047 & -0.876 & -0.719 & -1.571 & 1.767 \\
\hline skin permeation & -5.420 & -0.102 & -0.457 & -0.324 & -2.680 & 2.066 \\
\hline permeation into cerasome & -1.922 & 0.200 & -0.629 & -0.109 & -1.451 & 1.757 \\
\hline egg lecithin bilayer & 0.347 & 0.530 & -1.740 & -2.631 & -4.406 & 4.223 \\
\hline$\% \mathrm{HIA}^{a}$ & 90.32 & 0.00 & 0.00 & -15.65 & -21.15 & 17.16 \\
\hline \multicolumn{7}{|c|}{ Environmental Processes } \\
\hline water to soil & 0.21 & 0.74 & 0.00 & -0.31 & -2.27 & 2.09 \\
\hline water to Pahokee peat & -0.29 & 0.81 & -0.61 & -0.21 & -3.44 & 2.99 \\
\hline water to poly(dimethylsiloxane) & 0.268 & 0.601 & -1.416 & -2.523 & -4.107 & 3.637 \\
\hline water to poly(oxymethylene) & -0.37 & 0.39 & 0.28 & -0.46 & -3.98 & 2.98 \\
\hline water to the gas phase & 0.994 & -0.577 & -2.549 & -3.813 & -4.841 & 0.869 \\
\hline
\end{tabular}

${ }^{a}$ Human intestinal absorption expressed as the percentage of compound absorbed. 
Bronner and Goss ${ }^{34}$ for one particular soil (Pahokee peat) and the coefficients found by Poole and Poole ${ }^{35}$ for sorption into soil in general. Also included are coefficients for distribution from water to two polymers used in solid-phase microextraction, poly(dimethylsiloxane) ${ }^{36}$ and poly(oxymethylene). ${ }^{37}$ The important air-water distribution is usually given in terms of partition from the gas phase to water, but for consistency we give equation coefficients for partition from water to the gas phase. ${ }^{38}$ Apart from the latter process, where the very large effect of intraHB is as expected, it is very difficult to predict the effect of intraHB. Even for the two sorbents used in solid-phase microextraction, the effect can be very large [water to poly(dimethylsiloxane)] or almost negligible [water to poly(oxymethylene)]. Thus, as found for the permeation processes, in order to gauge the effect of intraHB, knowledge of the details of the process involved is essential.

\section{CONCLUSION}

Our NMR method for the determination of the descriptor $A$ is a very simple method of assessing the presence of an intraHB in a molecule. However, the effect of incorporating an intraHB in a molecule on the actual values of physicochemical and biochemical properties is not obvious, and some method that relates intraHBs to such properties is a necessary requirement in order to establish the effect of intraHB. We have used a particular method based on eq 2 , but in principle any method that can connect a structural feature such as an intraHB to the value of some property could be used. As a simple practical guide, phases could be classified into those that are strongly hydrophobic (heptane, chloroform, tetrachloromethane, toluene, nitrobenzene, egg lecithin bilayers), those that are moderately hydrophobic (dibutyl ether, brain, skin, cerasome), and those that are weakly hydrophobic (octanol, intestinal membrane). Then once the presence of an intraHB is detected using the NMR method, an assessment of the actual effect of intraHB can be deduced as strong, medium, and weak, respectively.

\section{EXPERIMENTAL SECTION}

The determination of NMR chemical shifts was carried out exactly as described previously. ${ }^{19-21}$

\section{AUTHOR INFORMATION}

\section{Corresponding Author}

*E-mail: m.h.abraham@ucl.ac.uk.

\section{Notes}

The authors declare no competing financial interest.

\section{ACKNOWLEDGMENTS}

W.L.W. is thankful for the financial support of the Welch Foundation Departmental Research Program and the Tarleton Organized Research Grant Program.

\section{REFERENCES}

(1) Shalaeva, M.; Caron, G.; Abramov, Y. A.; O’Connell, T. N.; Plummer, M. S.; Yalamanchi, G.; Farley, K. A.; Goetz, G. H.; Philippe, L.; Shapiro, M. J. J. Med. Chem. 2013, 56, 4870-4879.

(2) El Tayar, N.; Tsai, R.-S.; Testa, B.; Carrupt, P.-A.; Leo, A. J. Pharm. Sci. 1991, 80, 590-598.

(3) El Tayar, N.; Testa, B.; Carrupt, P.-A. J. Phys. Chem. 1992, 96, $1456-1461$.

(4) El Tayar, N.; Mark, A. E.; Vallat, P.; Brunne, R. M.; Testa, B.; van Gunsteren, W. F. J. Med. Chem. 1993, 36, 3757-3764.
(5) Steyaert, G.; Lisa, G.; Gaillard, P.; Boss, G.; Reymond, F.; Girault, H. H.; Carrupt, P.-A.; Testa, B. J. Chem. Soc., Faraday Trans. 1997, 93, 401-406.

(6) Leo, A. J. J. Pharm. Sci. 2000, 89, 1567-1578.

(7) Feng, L.; Han, S.; Wang, L. Chin. Sci. Bull. 1996, 41, 732-735.

(8) Abraham, M. H. Chem. Soc. Rev. 1993, 22, 73-83.

(9) Abraham, M. H.; Ibrahim, A.; Zissimos, A. M. J. Chromatogr., A 2004, 1037, 29-47.

(10) Abraham, M. H.; Smith, R. E.; Luchtefeld, R.; Boorem, A. J.; Luo, R.; Acree, W. E., Jr. J. Pharm. Sci. 2010, 99, 1500-1515.

(11) Clarke, E. D.; Mallon, L. J. The Determination of Abraham Descriptors and Their Application to Crop Protection Research. In Modern Methods in Crop Protection Research; Jeschke, P., Kramer, W., Schirmer, U., Witschel, M., Eds.; Wiley-VCH: Weinheim, Germany, 2012; pp 273-279.

(12) Abraham, M. H.; Acree, W. E., Jr. Eur. Chem. Bull. 2013, 2, $1027-1037$.

(13) COSMOtherm_BP-TZVP_C21_0111, 2013.

(14) SPARC: http://ibmlc2.chem.uga.edu/sparc/.

(15) Goetz, G. H.; Farrell, W.; Shalaeva, M.; Sciabola, S.; Anderson, D.; Yan, J.; Philippe, L.; Shapiro, M. J. J. Med. Chem. 2014, 57, 29202929.

(16) Abraham, M. H.; Abraham, R. J.; Byrne, J.; Griffiths, L. J. Org. Chem. 2006, 71, 3389-3394.

(17) Whaley, W. L.; Okoso-amaa, E. M.; Womack, C. L.; Vladimirova, A.; Rogers, L. B.; Risher, M. J.; Abraham, M. H. Nat. Prod. Commun. 2013, 8, 85-98.

(18) Siskos, M. G.; Kontogianni, V. G.; Tsiafoulis, C. G.; Tzakos, A. G.; Gerothanassis, I. P. Org. Biomol. Chem. 2013, 11, 7400-7411.

(19) Abraham, R. J.; Griffiths, L.; Perez, M. Magn. Reson. Chem. 2013, $51,143-155$.

(20) Abraham, R. J.; Griffiths, L.; Perez, M. Magn. Reson. Chem. 2014, $52,395-408$.

(21) Abraham, R. J.; Byrne, J. J.; Griffiths, L.; Perez, M. Magn. Reson. Chem. 2006, 44, 491-509.

(22) Abraham, R. J.; Mobli, M. Magn. Reson. Chem. 2007, 45, 865877.

(23) (a) Pouchert, C. J.; Behnke, J. The Aldrich Library of ${ }^{13} \mathrm{C}$ and ${ }^{1} \mathrm{H}$ FT-NMR Spectra, 1st ed.; Aldrich Chemical Company, 1993. (b) AIST:RIO-DB01 Spectral Data Base for Organic Compounds, SDBS, 2010.

(24) Biali, S. E.; Rappoport, Z. J. Am. Chem. Soc. 1984, 106, 56415653.

(25) Lessene, G.; Smith, B. J.; Gable, R. W.; Baeli, J. B. J. Org. Chem. 2009, 74, 6511-6525.

(26) PCModel, version 9.2; Serena Software: Bloomington, IN, 2007.

(27) Absolv, version 5.0; Advanced Chemistry Development: Toronto, ON.

(28) Mazák, K.; Noszál, B. Eur. J. Pharm. Sci. 2014, 62, 98-104.

(29) Livingston, D.; Davis, A. Modeling Chemical Structure-Log P. In Drug Design Strategies: Quantitative Approaches; Royal Society of Chemistry: London, 2012; Chapter 7, p 192.

(30) Abraham, M. H. J. Pharm. Sci. 2014, 103, 956-1966.

(31) Abraham, M. H. J. Pharm. Sci. 2011, 100, 1690-1701.

(32) Zhang, K.; Chen, M.; Scriba, G. K. E.; Abraham, M. H.; Fahr, A.; Lui, X. J. Pharm. Sci. 2011, 100, 3105-3113.

(33) Zhang, K.; Chen, M.; Scriba, G. K. E.; Abraham, M. H.; Fahr, A.; Lui, X. J. Pharm. Sci. 2012, 101, 2034-2044.

(34) Bronner, G.; Goss, K.-U. Environ. Sci. Technol. 2011, 45, 13131319.

(35) Poole, S. K.; Poole, C. F. J. Chromatogr., A 1999, 845, 381-400.

(36) Sprunger, L.; Proctor, A.; Acree, W. E., Jr.; Abraham, M. H. J. Chromatogr., A 2007, 1175, 162-173.

(37) Endo, S.; Hale, S. E.; Goss, K.-U.; Arp, H. P. H. Environ. Sci. Technol. 2011, 45, 10124-10132.

(38) Abraham, M. H.; Andonian-Haftvan, J.; Whiting, G. S.; Leo, A.; Taft, R. W. J. Chem. Soc., Perkin Trans. 2 1994, 1777-1791. 